\title{
Concise argument—wellbeing, collective responsibility and ethical capitalism
}

This is a special issue for two reasons. Firstly, it is the first issue of my extension as Editor-in-Chief of the Journal of Medical Ethics until May 2018. I would like to thank the Institute of Medical Ethics and BMJ. I would also like to welcome Dr Tom Douglas and Associate Professor Dominic Wilkinson as lead editors. The Editorial team, all of whom have done a fantastic job, will remain the same for our last two years.

Secondly, this is an Editors' Choice Issue. The Editors and Associate Editors each invited one contributor of their choice. Our self-imposed brief was to concentrate on excellent but less well-known scholars from a variety of perspectives, especially those who are young and up and coming, alongside some more established contributors. We gave them no topic direction and it is interesting that their contributions aggregate naturally around four perennial clusters: the concept of the good life, end of life, public health and new technologies (enhancement/selection).

James Wilson argues for a right to public health as risk reduction (see page 367). He argues that the right to public health is analogous to the right to security.

The right to public health entails that individuals have an entitlement that their governments systematically remove threats to human health by undertaking health protection and promotion measures. For example, we are all subject to infringements of liberty and inconvenience for airport security-including searches of our person and luggage. This is justified not because it guarantees our safety but because it lowers our risk collectively. So, public health measures, such as limiting soda portion sizes, could be justified if they promoted public health because we have a right to public health, just as we have a right to security.

I agree with much of Wilson's argument but I am not sure that it helps to say we have a right to public health. Rather we have a strong (pro tanto) moral obligation

Correspondence to Julian Savulescu, The Oxford Uehiro Centre for Practical Ethics, Department of Faculty of Philosophy, Oxford, UK; julian.savulescu@ philosophy.ox.ac.uk to support public health measures because there is a moral reason.

Morality is different from prudence. Morality is "other regarding" while prudence or self-interest is purely selfregarding. To have a moral duty is to have a duty to others. It is at the core of morality that it requires a minimal level of altruism or self-sacrifice. The circumstances, degree and other aspects of sacrifice are the subject of great debate and differ with differing moral theories.

A minimal theory of moral obligation can be called a "duty of easy rescue". Peter Singer illustrates it: "if I am walking past a shallow pond and see a child drowning in it, I ought to wade in and pull the child out. This will mean getting my clothes muddy, but this is insignificant, while the death of the child would presumably be a very bad thing". ${ }^{1}$

The duty of easy rescue can be formalised. When the cost to $\mathrm{X}$ of performing some action, $\mathrm{V}$, is small, and the benefit to $\mathrm{Y}$ is large, then $\mathrm{X}$ ought to $\mathrm{V}$.

This principle can take a collective form. Call this Collective Easy Rescue or Collective Responsibility: If a group of people $(\mathrm{X} 1 \ldots \mathrm{Xn})$ could all perform some act, V, which would collectively provide a large benefit to $\mathrm{Y}$, then this group (X1 ... $\mathrm{Xn}$ ) ought to $\mathrm{V}$, provided that the cost to each of them of $\mathrm{V}$-ing is small.

An example of $\mathrm{V}$ is vaccination. It imposes small costs on an individual to create herd immunity, a collective good. In the case of public health interventions such as limitations on soda sizes, we have an obligation to subject ourselves to the inconvenience of ordering a second soda for the sake of the public good, just as we have an obligation to subject ourselves to airport screening, as Wilson argues. We have a collective responsibility for public health and security.

Bayer and Fairchild give a subtle analysis of fear-based strategies in health promotion, against a comprehensive history of the ethics of public health (see page 391). They conclude that available evidence suggests fear-based campaigns work, but risk stigmatising and harming those who cannot or will not change. They conclude that such campaigns can be justified if part of a broader comprehensive approach and their justification is transparent and there is sufficient consultation.

This paper raises the important question: What happens to "duty" when the "rescue" is not easy? That is, the policy imposes significant costs on one group, say through the stigmatising of smokers or obese people by fear-based campaigns that arouse emotions of disgust. This issue also comes up in Sean Aas and Candice Delmas' paper where they consider potential sexual orientation alteration therapies. These might benefit individuals significantly but cause collateral damage by further stigmatising LGBT communities. They call this a 'clinical collective action problem'. They are against any applied research into sexual orientation and in favour of a precautionary approach to basic research (see page 340).

Both of these approaches to the problem of collective "difficult rescue" are, in my view, inconsistent with the way we deal with this phenomenon elsewhere. Many practices which are beneficial to some individuals risk stigmatising groups and inflicting significant harm on them as a result. Ana Iltis gives the example of genetic selection and modern eugenics. She gives five reasons to believe this is not significantly different from old style, discredited eugenics of the late nineteenth and early twentieth century. Indeed, she argues convincingly that social goals, "public health" and cost-effectiveness remain important drivers of genetic screening and testing programmes (see page 334).

One objection to pre-natal genetic screening and testing is that it stigmatises groups who are frequently selected against, for example those with Down syndrome. They may be perceived as avoidable costly mistakes, and as there are fewer people born with Down syndrome, fewer resources are devoted to supporting them. So while screening may benefit significantly a couple who wish to have it, it could cause significant harm to people living with Down syndrome, just as fear campaigns could cause significant harm to those who live with AIDS or obesity.

The appropriate response to such significant costs is not to ban or restrict the 
practice. As Fairchild and Bayer argue, the practice should be part of a comprehensive approach. Not only should this require consultation and transparency, but it should also address the root causes of the problem. In the case of obesity, the root cause is the amoral nature of the market and the subsidies that effectively exist for producing unhealthy food. That is, food industry practice. In the case of Down syndrome or sexual orientation, the problem is discriminatory attitudes and practices.

Indeed, by also tackling these background injustices or bad practices through a comprehensive strategy, one converts a difficult rescue into an easy rescue. Call this cost conversion, from large to small.

As Wilson notes, one of the most effective public health measures has been taxation of tobacco and alcohol. Should a sugar tax be introduced and if so, how large should it be? The concept of collective responsibility and easy rescue are useful.

One objection to the sugar tax is that it is regressive and punishes those at the lower end of the socioeconomic spectrum. Sugary foods are cheap and readily available. Unlike a tobacco tax where someone can give up when it is too expensive, we must all eat. For those with little money or time, there are few practical equal or lesser cost alternatives to processed, often sugary foods. Any cost they are asked to bear is significant, not small.

The solution is again cost conversion, converting a large cost to a small cost. This could be achieved by making healthier food cheaper through subsidy.

This raises another intriguing public health issue. The cause of obesity and climate change is human behaviour resulting from human psychological bias and limitation. $^{2}$ Capitalism and the free market have been enormous drivers of innovation and progress. But markets are amoral. They don't aim for good outcomes. When humans use them in an unrestricted way, they can exploit human psychological weakness and limitation. For example, humans have a predilection for sugary, fatty and salty food. So if profit is the sole valued outcome, markets will create cheap palatable processed food.

For this reason, the market and capitalism need to be constrained. To achieve public health, healthy foods should be subsidized and unhealthy foods taxed. Companies would soon find a way to make profit out of marketing healthy foods, though their profit margins might be lower. Government ought to intervene in the market to achieve more ethical goals, such as promoting public health and well-being. This could be called ethical capitalism and is consistent with collective responsibility, or what Wilson calls a right to public health, or what we might call more broadly, if we wanted to use the language of rights, the right to a good life.

This brings us to another dominant theme in this issue: well-being or the good life or interests. Making progress on these topics is essential to establishing what we should be aiming at in promotion of well-being and in evaluating the extent of costs in public health. Though humans have considered this issue probably since they could first self-reflect, it has still not been resolved. How can we know what is good in life, in other people's lives, especially those radically different from our own? The two papers by Rodogno et al. (see page 401) and Robeyns (see page 383) both address what is good for autistic children while Gillon (see page 376) considers the interests of those with disorders of consciousness.

Both Rodogno et al and Robeyns call for more person-specific accounts of wellbeing. Both draw attention to the different kinds of relationships children with autism have and can derive pleasure and value from. Rodogno et al call for "experiments in living" in order to find what is good for a particular child with autism while Robeyns argues for a broad capabilities approach referring to Nussbaum's account.

It must surely be correct that evaluations of well-being are highly context dependent. What is good for one person is not necessarily good or as good for another. And this is especially the case in "neurodiverse" people. When aiming to promote the best interests approach, a wide and flexible capability or objective list approach is surely desirable.

A particularly acute and unresolved issue is when life is no longer worth living. That is, when the level of wellbeing is so low that it is no longer in that individual's interests to live. Gillon considers the cases of persistent vegetative state (PVS) and minimally conscious state (MCS) (see page 379). He argues that there is inconsistency in recent English judicial decisions and that doctors are not obliged to provide life prolonging treatment or artificial feeding and nutrition if they and the family believe it is not in the interests of their patients. He follows a recent Supreme Court judgement in that such decisions should rely on the fact that "Mental Capacity Act's tests for 'best interests' contain “a strong element of 'substituted judgment'”.
Gillon argues for, in effect, a subjective account of best interests where a person's interests are largely or entirely derived from their preferences or desires. In my view, substituted judgement should be kept separate from interests, and autonomy should not be a part of interests. The reason for that is that we can be mistaken about our own interests. Just because a person desires $\mathrm{X}$ (e.g. to eat a lot) does not make $\mathrm{X}$ good. We should adopt an objective account of interests in line with that suggested by Rodogno et al and Robeyns.

Now is life in a MCS worth living? Gillon would have us answer this question by consulting the desires of the person who lives that life. I have myself written that such a life could be a hell. ${ }^{3}$ However, I must confess I don't know. As I have written elsewhere, judgements of whether life is worth living are notoriously difficult to make. ${ }^{4}$

We can be much more confident in making two other relevant judgements. One is whether a person would want to live in a MCS. In the case of $\mathrm{W} v \mathrm{M}$ which Gillon cites, there was evidence that the patient would not have wanted to live in a MCS. People should be able to refuse medical treatment and withdrawal of medical treatment should also be made on the basis of substituted judgement.

A second issue is whether limited resources should be spent on keeping patients with disordered consciousness alive. Dominic Wilkinson and I have argued that futility judgements are best interpreted as judgements about limited resources and distributive justice. ${ }^{5}$

It is a mistake, in my view, to conflate respect for autonomy with beneficence. If one takes a highly subjective account of interests, these become conflated. Consider a Jehovah's Witness who needs a life-saving blood transfusion. A transfusion is in her best interests though she may legitimately refuse it. It would be absurd to suggest that her life would not be worth living if she were transfused, as a subjective account of interests maintains.

It is not because a life in MCS is not worth living that we should let such patients die. It is when they would not have wanted to live such a life or because it is an unjust use of limited resources. In my view, such decisions should separate an objective conception of interests, respect for autonomy and justice. We have enough tools in our kit to account for the cases Gillon raises. And, as he correctly suggests, such decisions would more effectively be facilitated by 
forming advance directives (indeed, see his own fascinating advance directive online: http://jme.bmj.com/content/early/ 2016/04/26/medethics-2016-103538/

DC1/embed/inline-supplementary-material-1.pdf).

End of life is an important theme in this issue. Merkel addresses the important issue of the moral status of actively withdrawing life-prolonging medical treatment (see page 353) and Gavaghan offers a novel interpretation of the Doctrine of Double Effect, developing a recent New Zealand legal decision that possibly opens the door to assistance in dying that focuses on intention (see page 361). Walker argues that justice requires combating the decline in capacities associated with aging with human enhancement (see page 348).

The mark of good philosophy is not that you agree with it, not even necessarily that it is right or true, but that it provokes you to think. All the papers in this issue are examples of good philosophical medical ethics.

\section{REFERENCES}

1 Singer P. Famine, Affluence, and Morality. Philos Public Aff 1972; 1:229-43.
2 Savulescu J, Persson I. Unfit for the Future: The Need for Moral Enhancement Oxford: Oxford University Press 2012.

3 Kahane G, Savulescu J. Brain-Damage and the Moral Significance of Consciousness'. J Med Philos 2009;34:6-26.

4 Savulescu J. Autonomy, Interests, Justice and Active Medical Euthanasia In: eds. Chobi M, Varelius J, New Directions in the Ethics of Assisted Suicide and Euthansia. New York: Springer 2015: 41-58.

5 Wilkinson D, Savulescu J. Knowing when to stop: futility in the ICU. Curr Opin Anaesthesiol 2011;24:160-65. 